Archimer, archive institutionnelle de l'ffremer

Vol. 252, Issues 2-4 , 10 March 2006, Pages 462-475

http://www.ifremer.fr/docelec/

http://dx.doi.org/10.1016/j.aquaculture.2005.07.004

(c) 2005 Elsevier B.V. All rights reserved

\title{
No efficiency of the lateral system on nocturnal feeding in the European sea bass (Dicentrarchus labrax L.)
}

\author{
Karine Faucher ${ }^{\mathrm{a}, \mathrm{b},{ }^{\star}}$, Gilbert Dutto ${ }^{\mathrm{c}}$, Denis Covès ${ }^{\mathrm{c}}$, Anne Aubert $^{\mathrm{b}}$ and Jean Paul Lagardère ${ }^{\mathrm{a}}$
}

\begin{abstract}
${ }^{a}$ Centre de Recherche sur les Ecosystèmes Marins et Aquacoles, CNRS-Ifremer, BP 5, 17137
L'Houmeau, France

${ }^{\mathrm{b}}$ Laboratoire de Biologie et Environnement Marins, FRE 2727, CNRS-Université de La Rochelle, Avenue Michel Crépeau, 17042 La Rochelle, France

${ }^{\mathrm{c}}$ Station expérimentale d'aquaculture IFREMER, Laboratoire de Recherche Piscicole de Méditerranée, Chemin de Maguelone, 34250 Palavas les Flots, France
\end{abstract}

*: Corresponding author : kfaucher@univ-Ir.fr

\begin{abstract}
:
In order to evaluate the effect and consequence of lateral system inactivation on fish nocturnal feeding, the differential growth of groups of European sea bass maintained in different rearing conditions were compared. Whereas some fish with intact lateral system (placebo fish) were placed under a photoperiod of $12-\mathrm{L}: 12-\mathrm{D}$, other placebo fish were kept in the dark. In the same way, fish deprived of lateral system by section of their lateral system nerves and antibiotic treatment were placed under a photoperiod of 12-L : 12-D and the others in the dark. For each of these four rearing conditions, two sets of experiment were realized. Percent mortality, feed rhythm, averaged daily feed demand, specific growth rate and feed efficiency were compared among these four groups of fish. After four months of experiment, results revealed that, under a photoperiod of $12-\mathrm{L}: 12-\mathrm{D}$, fish showed a diurnal feed rhythm whereas no rhythm appeared in fish kept in the dark. In addition, as reported by other authors, the average daily feed demand, the quantity of ingested food and specific growth rate were greater in fish maintained under a photoperiod of 12-L : 12-D than those kept in the dark. The fish lateral system inactivation did not affect mortality, feed intake, specific growth rate or feed efficiency. These results demonstrated that lateral system is not the major sensory organ leading to European sea bass nocturnal feeding; chemoreception system undoubtedly taking over. If the olfactory system explains equal feed intake between placebo and treated fish, the greater specific growth rate in treated than in placebo fish indicates the action of another mechanism, such as a "booster effect" of antibiotics used for lateral system inactivation on fish.
\end{abstract}

Keywords: European sea bass; Lateral system; Photoperiod; Nocturnal feeding; Growth; Feed efficiency 


\section{Introduction} .

Fish feeding behavior proceeds from the interaction of sense organs receptive to visual, mechanical, chemical and electromagnetic stimuli (Hyatt, 1979; Pavlov and Kasumyan, 1990; Cobcroft and Pankhurst, 2003; Liao and Chang, 2003). The role and function of each stimuli are relatively well documented (see Fernald, 1988 for sight; Atema, 1988; Hara, 1993; Lamb, 2001 for chemoreception; Enger et al., 1989; Montgomery, 1989 for mechanoreception; Tavolga, 1977 for sound). According to Hyatt (1979) and New et al. (2001), there is a hierarchy of sensory system dominance during prey strike. Vision is involved in the initial location of and orientation to the prey whereas the lateral system is of primary importance in the approach at small distances and during the final stage of the prey strike. Loss of one of these sensory systems may lead to a sensory compensation, involving an increased sensitivity of other sensory organs (Pavlov and Kasumyan, 1990). In addition, according to fish species or within the same species, this feeding behavior has to be functional during the day as well as at night. For example, under rearing conditions, European sea bass presents a diurnal feed rhythm in spring and summer but a nocturnal one in autumn and winter (Sanchez-Vasquez et al., 1995a, b, 1998; Boujard et al., 1996; Rubio et al., 2004). This duality in feeding behavior in some fish species requires sensory relays. In this way, under conditions of reduced vision, some mechanisms of sensory compensation involving chemoand mechanoreception take over to allow feeding (Pavlov and Kasumyan, 1990; Montgomery and Milton, 1993; McDowall, 1997; Montgomery and Hamilton, 1997; Liang et al., 1998) but seemingly with a lower efficiency. In particular, while the fish lateral system facilitates nocturnal feeding, it is even more efficient in the localization of moving living prey (Hoekstra and Janssen, 1986; Montgomery, 1989; Bleckmann, 1993; Liang et al., 1998; Pohlmann et al., 2004) than in the search for inert food (Liao and Chang, 2003). Although olfaction can 
stimulate fish in their search for food (New et al., 2001), it is not by itself enough to allow a fish to localize and catch a moving living prey in the dark (Enger et al., 1989; New et al., 2001; Pohlmann et al., 2004).

Pavlov and Kasumyan (1990) divided the feeding behavioral process into three stages: 1) receipt by the individual of a signal on the presence of food, 2) search for and localization of the source of the signal and 3) determination of the suitability of the food. This functional scheme could not be applied as simply in intensive European sea farming conditions. In this study, the European sea bass has to identify and actuate a triggering system to supply the fish with pellets from a self-feeder. Nocturnal feeding, that occurs in this fish species under rearing conditions as in the natural environment, shows us that fish use an unknown sensory mechanism to locate the food source in total darkness (prey, or the tactile rod in rearing conditions), and to catch the food (natural prey, or pellets in rearing conditions). Sanchez-Vasquez et al. (1995b), Coves et al. (1998) and Rubio et al. (2003) have suggested an important involvement of the European sea bass lateral system in the feeding performance. The aim of this study was to determine the implications of mechanoreception in nocturnal feeding behavior in this fish species. For this, differences between the triggering activity and feed intake on a population scale and growth on an individual scale was examined in individuals as a function of: 1) whether their lateral system was intact or damaged; 2) illumination regime (total darkness or alternation day and night).

\section{Materials and methods}

\subsection{Animal origin, housing and fish tagging}


Experiments took place between February and June 2003. Five hundred twenty hatchery reared European sea bass (Dicentrarchus labrax), weighing about $150 \mathrm{~g}$, were obtained from a commercial source (Méditerranée pisciculture, France).

In order to tag individual fish, they were anaesthetized with $0.08 \mathrm{ml} \mathrm{l}^{-1}$ clove essence (EUGENOL, Rhône-Poulenc) for several minutes. PIT-tags were placed under the skin anterior to the dorsal fin. This tagging allowed us to identify each fish to follow individual growth (length and weight).

Sea bass were stocked as groups of 40 fish in 13 seawater $1 \mathrm{~m}^{3}$-tanks at constant temperature $\left(22^{\circ} \mathrm{C}\right)$ in open circuit with a photoperiod of 12-L:12-D for four weeks. Incandescent lamps were positioned above each tank. Dawn (06:00) and dusk (18:00) were simulated by progressively increasing and decreasing the light intensity, over $30 \mathrm{~min}$ in the morning and evening to recreate natural environment conditions.

After this acclimation period, the lateral system of half of the fish was inactivated. Animals were then distributed in order to obtain tanks with $100 \%$ intact lateral system fish (placebo fish), tanks with $100 \%$ inactivated lateral system fish (treated fish) and mixed tanks with $50 \%$ placebo fish and $50 \%$ treated fish. In order that all fish learn to activate the selffeeder in an optimal manner, all tanks were maintained at the photoperiod of 12-L:12-D for one week after lateral system inactivation. Then, 6 tanks of fish (2 tanks with placebo fish, 2 with treated fish and 2 mixed tanks) were subjected to total darkness for the rest of the experiment. For each photoperiod, two replicates (sets) were realized. An additional mixed tank, maintained under the photoperiod of 12-L:12-D, was put aside for fish sampling in order to verify the histological state of their neuromasts after lateral system inactivation.

Fish were fed using a self-feeder (IMETRONIC) with a tactile sensor, positioned a few centimeters below the water surface, connected to a computerized interface that recorded 
feed demands (date, time). To obtain food, fish in each tank had to bite and pull a string sensor (Rubio et al., 2004).

\subsection{Sea bass lateral system inactivation}

To ensure a maximal destruction of both types of lateral system neuromasts during the duration of the experiment, two treatments were applied: the section of the nerves innervating the lateral system was followed by an antibiotic treatment. Two hundred sixty fish were anaesthetized with $0.08 \mathrm{ml} \mathrm{l}^{-1}$ clove essence for several minutes and placed individually on a submerged operating table. They were immerged during the entire duration of the surgery. On each side of the fish, the two nerves (anterior and posterior) innervating the lateral system were cut at the level of the opercula. These nerves connect the lateral system to the central nervous system. The anterior lateral nerve is located in front of the stato-acoustic nerve and innervates most of the lateral system organs of the head. The posterior lateral nerve is found behind the stato-acoustic nerve. Its branches run together with the vagus nerve for short distances but is not considered as portions of this nerve. It innervates the lateral system organs of the occipital, troncal and caudal areas (Harder, 1975; Ghysen and DamblyChaudière, 2004). After this surgery, conducted within 3 min per fish, local antiseptic solution (Betadine) was applied to the wounds. For fear of the cephalic lateral system not being completely inactivated, the surgery technique was followed by an antibiotic bath. After allowing them several minutes to recover, the fish were then placed in a tank filled with seawater containing $42 \mathrm{mg} \mathrm{l}^{-1}$ gentamicin sulfate (Sigma) and $0.5 \mathrm{~g} \mathrm{l}^{-1}$ streptomycin sulfate (Sigma) for $3 \mathrm{~h}$. Fish were then released into their respective experimental tanks. In order to prevent regeneration of lateral system neuromasts after the antibiotic treatment (Kaus, 1987; 
Blaxter and Fuiman, 1989; Song et al., 1995; Coombs et al., 2001), treatment was repeated each month after weighing.

Control or placebo fish were subjected to the same handling and anaesthetizing procedures in order to reproduce the same stress as fish that underwent surgery. After recovering from the anesthesia, placebo fish were placed into seawater tanks without any antibiotic for $3 \mathrm{~h}$. They were then released into their respective experimental tanks. Each month, after the weighing, placebo fish underwent the same handling to reproduce the same stress as the treated fish.

\subsection{Measurement of fish growth}

Food was provided on-demand by the fish actuating the string sensor. The quantity of pellets distributed at each activation was constant. The uneaten pellets during their descent through the column water could remain for up to 15 min on the tank bottom. The cap-shaped bottom of the tanks allowed for the recovery of uneaten pellets. Coves et al. (1998) and Rubio et al. (2004) gived a scheme of this feeding system.

Each month, each fish group was anaesthetized with $0.08 \mathrm{ml} \mathrm{l}^{-1}$ clove essence, identified by PIT-tag reading, measured and weighed.

\subsection{Lateral system functional status checking}

On three occasions (at the beginning, middle and at the end of the experiment), two sea bass (a placebo and a treated fish) were collected to observe both types of neuromasts from their trunk lateral line system using scanning electron microscopy. These fish were 
anaesthetized with $0.08 \mathrm{ml} \mathrm{l}^{-1}$ clove essence. Both entire trunk lateral lines were isolated and immediately fixed in 4\% glutaraldehyde (Fisher Scientific Labosi) in sodium cacodylate buffer (0.4 M, pH 7.2). Some scales were left intact in order to observe superficial neuromasts whereas the roof of the canal segment of others were carefully removed to allow visualization of canal neuromasts. Tissue samples were then dehydrated through graded acetone concentrations and critical point-dried using liquid $\mathrm{CO}_{2}$ (BALTEC CPD 030). They were then mounted on brass supports and sputter coated with gold (Cressington Sputter Coat). Observations were performed with a JEOL JSM-5410LV scanning electron microscope.

\subsection{Data processing and statistical analyses}

Percent mortality was calculated according to lateral line status and photoperiod condition. For mixed tanks, the individual tagging of fish allowed their identification. The mortality of treated and placebo fish was then calculated independently. Percent mortality was compared using a homogeneity chi-square test.

The feed demand rhythm was examined according to illumination regime and lateral system status. Then, feeding activity was quantified by recording the number of feed demands per day (activation of the self-feeder) according to the two factors, photoperiod and treatment. As these data were not normally distributed $(\mathrm{P}<0.0001)$, they were compared with nonparametric tests: Kruskall-Wallis (noted as H) and Mann-Whitney (noted as U).

The uneaten pellets were counted and used to assess the amount of food ingested, according to equation 1 . 
For each photoperiod and treatment, the percentage feed intake, (the amount of food ingested per $100 \mathrm{~g}$ of average fish body weight) was calculated. Percentages obtained were normally distributed $(\mathrm{P}=0.089)$, they were consequently compared with an analysis of variance (ANOVA) with two factors: photoperiod (darkness and 12-L:12-D) and treatment (placebo fish, treated fish, mixed tank fish) followed by a parametric multiple comparison test $\mathrm{t}$ of Student-Newman-Keuls (SNK).

Growth of each group of fish was evaluated through the calculation of their monthly specific growth rate (SGR) according to equation 2 (Coves et al., 1998) and according to photoperiod and treatment.

$\mathrm{SGR}=\left(\left(\left(\ln\right.\right.\right.$ biomass $\left.\mathrm{m}_{\mathrm{f}}\right)-\left(\ln\right.$ biomass $\left.\left.\mathrm{m}_{\mathrm{i}}\right)\right) /$ time $) \times 100$

where biomass $m_{\mathrm{f}}$ is the final biomass at the end of each month, and biomass $\mathrm{m}_{\mathrm{i}}$ is the initial biomass at the beginning of each month.

In addition, the overall specific growth rate $\left(\mathrm{SGR}_{\mathrm{o}}\right)$, for the duration of the experiment, was calculated from equation 3 according to photoperiod and treatment.

$$
\operatorname{SGR}_{\mathrm{o}}=\left(\left(\left(\ln _{\text {biomass }} \mathrm{f}\right)-\left(\ln \text { biomass }_{\mathrm{i}}\right)\right) / \text { time }\right) \times 100
$$

where biomass $\mathrm{f}_{\mathrm{f}}$ is the final biomass at the end of the experiment, and biomass $_{\mathrm{i}}$ is the initial biomass at the beginning of the experiment. 
treatment (placebo fish, treated fish, mixed tank fish) as the two factors, followed by a parametric multiple comparison t test of Student-Newman-Keuls (SNK).

The feed efficiency referring to feed intake was estimated according to photoperiod and treatment according to equation 4 and is expressed as percentages.

Feed efficiency $=\left(\right.$ biomass $_{\mathrm{f}}-$ biomass $\left._{\mathrm{i}}\right) \times 100 /$ amount of food ingested

treatment) were not normally distributed $(\mathrm{P}<0.0001)$, they were compared by non-parametric tests: H for Kruskall-Wallis and U for Mann-Whitney.

All statistical tests were conducted with the XIStat-Pro 6.0 statistical analysis software. The significance was calculated at $\mathrm{P}<0.05$.

\section{Results}

\subsection{Neuromast tissues of treated sea bass}

Fig. 1 shows the histological state of superficial and canal neuromasts of placebo sea bass (Fig. 1 A, B) and of treated sea bass (Fig. 1 C, D). Compared with placebo fish, both types of neuromasts of treated fish were damaged. Indeed, their maculae presented a total disorganization of the hair bundles of underlying hair cells. In some cases, hair bundles were much dispersed or totally destroyed. 


\subsection{Rejection of incoherent data}

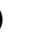
maintained in continuous darkness) had to be rejected. In this tank, feed intake was unusually low $(0.37 \%$ of their weight per day). The treatment alone could not be the reason for this feeding behavior: whatever were the treatment or the photoperiod, other fish presented a consumption of pellets equal to $0.87 \pm 0.13 \%(n=11)$ of their weight per day. An ANOVA followed by a multiple comparison test (SNK) revealed the existence of a significant difference between the quantity of ingested food by sea bass from this tank and those from other tanks $\left(\mathrm{F}_{11,36}=4.199, \mathrm{P}=0.001, \mathrm{n}=48\right)$. In addition, an ANOVA realized on specific growth rates (SGR) showed a significant difference between SGR of the different tanks $\left(\mathrm{F}_{11,36}\right.$ $=3.365, \mathrm{P}=0.003, \mathrm{n}=48)$. A multiple comparison test $(\mathrm{SNK})$ revealed that the difference observed was mainly due to the same tank (sea bass $100 \%$ treated and maintained in continuous darkness) $(0.17 \pm 0.15 \%, \mathrm{n}=4)$ for which values were significantly very different from data measured in other tanks $(0.60 \pm 0.18 \%, \mathrm{n}=44)(\mathrm{P}<0.046)$.

Given these results, we have rejected data from this tank in order not to overestimate the effect of sea bass lateral system inactivation on their nocturnal feeding behavior.

\subsection{Mortality}

$$
\text { treatment (table 1). Mortality was observed only at the beginning of the experiment (during }
$$
the first month); no death was recorded afterwards.

Among placebo fish, percent mortality was higher under a photoperiod of 12-L:12-D $(20.6 \%, \mathrm{n}=131)$ than in the dark $\left(6.3 \%, \mathrm{n}=127, \chi^{2}=11.264, \mathrm{P}=0.001\right)$. In contrast, treated 
sea bass maintained in the dark presented a percent mortality higher $(34.9 \%, \mathrm{n}=86)$ than those under the photoperiod of 12-L:12-D $\left(16.9 \%, \mathrm{n}=83 ; \chi^{2}=7.119, \mathrm{P}=0.008\right)$. Under a photoperiod of 12-L:12-D, the difference observed among the mortality of placebo sea bass $(20.6 \%, \mathrm{n}=131)$ and treated sea bass $(16.9 \%, \mathrm{n}=83)$ was not significant: over both treatments, the percent mortality was the same $\left(\chi^{2}=0.460, P=0.498\right)$. In contrast, in the dark, treated sea bass presented a percent mortality $(34.9 \%, \mathrm{n}=86)$ higher than placebo sea bass $\left(6.3 \%, \mathrm{n}=127 ; \chi^{2}=29.098, \mathrm{P}<0.0001\right)$.

\subsection{Feed rhythm}

The daily feed rhythm of sea bass is shown according to photoperiod regimes (table 1; 12-L:12-D, in Fig. 2A, and darkness, in Fig. 2B). Fish subjected to 12-L:12-D regime presented a daily feed rhythm markedly diurnal: $1.842 \pm 2.534$ diurnal feed demands $(\mathrm{n}=72)$ for $0.043 \pm 0.054$ nocturnal feed demands $(n=72)$. A Mann-Whitney test showed diurnal feed demand was significantly higher than nocturnal one $(\mathrm{U}=5171.000, \mathrm{P}<0.0001)$. In addition, maximal feed demand $(8.838 \pm 2.940$ feed demands, $n=6)$ was recorded at 6:00, that is during the artificial dawn. During the rest of the day, the number of feed demands progressively decreased until the artificial dusk (at 18:00). In continuous darkness, sea bass presented a constant daily feed rhythm over the 24 hours (Fig. 2B).

Whatever the photoperiod, treatment undergone did not modify sea bass feed rhythm: all fish subjected to 12-L:12-D showed a feed demand essentially diurnal whereas sea bass maintained in the dark presented a feed demand spread over the 24 hours. 


\subsection{Number of daily feed demands}

Considering the effect of photoperiod, average number of daily feed demand of sea bass maintained under the 12-L:12-D regime $(22.6 \pm 10.3, \mathrm{n}=660)$ was significantly higher than that recorded for fish kept in the dark $(16.0 \pm 9.7, \mathrm{n}=550 ; \mathrm{U}=249430.000, \mathrm{P}<0.0001$; Fig. 3A).

The average number of feed demand per day was then compared between sea bass from $0 \%$-treated tanks (placebos), mixed tanks and $100 \%$-treated tanks, under the 12-L:12-D regime and in the dark (table 1). As shown by figure 3A with a photoperiod of 12-L:12-D, average number of feed demand per day between placebo fish $(0 \%$ treated: $23.2 \pm 10.2, n=$ 220), fish from mixed tanks (50\% treated: $24.4 \pm 10.5, \mathrm{n}=220)$ and treated fish $(100 \%$ treated: $20.3 \pm 10.0, \mathrm{n}=220)$ were significantly different $(\mathrm{H}=20.537, \mathrm{P}<0.0001)$. Indeed, treated fish presented average number of feed demand per day significantly lower than that for sea bass from mixed tanks $(\mathrm{U}=18452.000, \mathrm{P}<0.0001, \mathrm{n}=440)$ as well as that of placebo fish $(\mathrm{U}=20017.000, \mathrm{P}=0.001, \mathrm{n}=440)$.

Significant difference was also observed in the dark between average number of feed demand per day for placebo fish $(16.8 \pm 10.7, \mathrm{n}=220)$, of fish from mixed tanks $(16.4 \pm 9 ., \mathrm{n}$ $=220)$ and treated fish $(13.5 \pm 7.5, \mathrm{n}=110 ; \mathrm{H}=7.558, \mathrm{P}=0.023$; Fig. $3 \mathrm{~A}$; table 1$)$. As under the 12-L:12-D regime, average number of feed demand per day for treated fish was significantly lower than that for fish from mixed tanks $(\mathrm{U}=10135.500, \mathrm{P}=0.008, \mathrm{n}=330)$ as well as that for placebo fish $(\mathrm{U}=9996.000, \mathrm{P}=0.005, \mathrm{n}=330)$.

In summary, sea bass maintained in the dark presented a feed demand lower than that for sea bass kept with a photoperiod of 12-L:12-D. In addition, this feed demand was less for treated fish than for fish from mixed tanks or placebo fish. 


\subsection{Feed intake}

Feed demands corresponded to food actually available. It was also necessary to examine the effect of photoperiod and / or treatment on the amount of food ingested by fish (Fig. 3B; table 1). Over the experiment, uneaten food represented only $0.15 \pm 0.13 \%(\mathrm{n}=11)$ of the total amount of food provided. Lateral system inactivation did not involve significant difference of percent uneaten food between placebo $(0.09 \pm 0.06 \%, \mathrm{n}=4)$, treated $(0.27 \pm$ $0.19 \%, \mathrm{n}=3)$ and fish from mixed tanks $(0.12 \pm 0.10 \%, \mathrm{n}=4 ; \mathrm{H}=2.506 ; \mathrm{P}=0.286 ; \mathrm{n}=$ 11). In contrast, the percent uneaten food was greater in fish maintained in continuous darkness $(0.23 \pm 0.14 \%, \mathrm{n}=5)$ than in fish subjected to a 12-L:12-D regime $(0.08 \pm 0.08 \%$, $\mathrm{n}=6 ; \mathrm{U}=3.500 ; \mathrm{P}=0.017 ; \mathrm{n}=11)$. All factors considered, sea bass ingested daily $0.87 \pm$ $0.22 \%(\mathrm{n}=44)$ of their fresh weight.

A two-factor (photoperiod and treatment) analysis of variance (ANOVA) revealed that photoperiod affected feed intake but that treatment did not. Indeed, with a photoperiod of 12-L:12-D, the average percentages of feed intake for all fish treatments $(0 \%, 50 \%$ and 100 $\%$ treated ones) was equal to $0.96 \pm 0.21 \%(\mathrm{n}=24)$ of their body weight. Then, if all sea bass kept in the dark are considered (in $0 \%$-treated, mixed and $100 \%$-treated tanks), percentage feed intake was significantly lower, $0.76 \pm 0.16 \%\left(n=20 ; F_{5,38}=12.535, P=0.001\right)$. In contrast, treatment did not modify feed intake. On average, all placebo sea bass (with photoperiod of 12-L:12-D and in the dark) presented average feed intake of $0.81 \pm 0.22 \%$ (n $=16)$ for $0.89 \pm 0.19 \%(\mathrm{n}=16)$ in all sea bass from mixed tanks (both photoperiods) and $0.92 \pm 0.24 \%(n=12)$ in the case of treated fish (both photoperiods together) $\left(\mathrm{F}_{5,38}=0.862\right.$ $\mathrm{P}=0.430)$. 


\subsection{Specific growth rate}

An ANOVA carried out on initial weights of sea bass from each tank showed no significant difference between tanks $\left(\mathrm{F}_{10,364}=1.587, \mathrm{P}=0.108, \mathrm{n}=375\right)$.

The overall specific growth rate $\left(\mathrm{SGR}_{\mathrm{o}}\right)$ of fish was compared for each photoperiod and each treatment (Fig. 4A; table 1). For all treatments, sea bass subjected to 12-L:12-D presented a $S_{G R}$ significantly higher $(0.67 \pm 0.16 \%, \mathrm{n}=196)$ than those kept in the dark $(0.50 \pm 0.14 \%, \mathrm{n}=175)\left(\mathrm{F}_{5,371}=122.418, \mathrm{P}<0.0001, \mathrm{n}=371\right)$. Under a photoperiod of 12$\mathrm{L}: 12-\mathrm{D}$, the $\mathrm{SGR}_{\mathrm{o}}$ of placebo fish $(0.66 \pm 0.19 \%, \mathrm{n}=70)$, of treated fish $(0.68 \pm 0.17 \%, \mathrm{n}=$ 56) and fish from mixed tanks $(0.67 \pm 0.13 \%, \mathrm{n}=70)$ did not vary significantly with treatment $\left(\mathrm{F}_{2,193}=0.182, \mathrm{P}=0.834, \mathrm{n}=195\right)$. In contrast, in the dark, placebo fish presented a $\mathrm{SGR}_{\mathrm{o}}$ significantly lower $(0.44 \pm 0.12 \%, \mathrm{n}=83)$ than that for fish from mixed tanks $(0.55 \pm$ $0.14 \%, \mathrm{n}=68 ; \mathrm{t}=4.490, \mathrm{P}<0.0001)$ and that for treated fish $(0.55 \pm 0.13 \%, \mathrm{n}=24 ; \mathrm{t}=$ $3.325 ; \mathrm{P}=0.001)$.

\subsection{Feed efficiency}

dark exhibited a $\mathrm{SGR}_{\mathrm{o}}$ higher than that for placebo sea bass as well as sea bass from mixed tanks. Consequently, it was interesting to compare feed efficiency between these three groups of fish (table 1; Fig. 4B).

For both photoperiod, sea bass presented a similar feed efficiency: $61.9 \pm 11.9 \%$ (n $=24)$ with a photoperiod of 12-L:12-D, and $60.8 \pm 10.2 \%(n=19)$ in the dark $(\mathrm{U}=266.000$, $P=0.353, n=43)$. Similarly, treatment had no significant influence on feed efficiency: placebo fish, fish from mixed tanks and treated fish displayed a feed efficiency equal to 60.31 
$\pm 11.55 \%(\mathrm{n}=16), 61.32 \pm 10.29 \%(\mathrm{n}=16)$ and $59.95 \pm 16.06 \%(\mathrm{n}=12)$ respectively $(\mathrm{H}=$ $1.068, \mathrm{P}=0.586, \mathrm{n}=43)$.

\section{Discussion}

\subsection{Efficiency of lateral system inactivation}

Before examining individual or pooled effects of photoperiod and lateral system inactivation, it was necessary to ensure that destruction of lateral system was total.

Observations realized by scanning electron microscopy indicated that almost all of both types of trunk lateral line neuromasts were destroyed after section of lateral system nerves followed by antibiotic treatment. In literature, studies did not mention any histological checking after lateral system nerve section (Pitcher et al., 1976; Partridge and Pitcher, 1980; Partridge, 1982; New et al., 2001). In addition, after antibiotic treatment, only some studies illustrated the histological tissue state of neuromasts (Song et al., 1995; Coombs et al., 2001) but with very few scanning electron micrographs. After this double treatment, and given the state of trunk lateral line neuromast tissues, one could easily admit that neuromasts of the whole body fish could be considered as non-functional.

Consequences of this sensory deficit were evaluated by percent mortality, specific growth rate and feed demand of sea bass according to photoperiod and treatment (inactivation or not of lateral system).

\subsection{Percent mortality}


Fish mortality only occurred during the first month of experiment. This early mortality, associated with the fact that under a photoperiod of 12-L:12-D, the mortality in treated fish was no different from that in placebo fish, indicates that deaths recorded could not be imputed to any deficiency of feed demand caused by inactivation of lateral system. This result also establishes that the double treatment, undergone by half the fish, was not too invasive. This early mortality can be in part explained by treatment conditions of sea bass during the first treatment at the beginning of the experiment. The stress caused by this manipulation associated with the higher fish density may have caused wounds leading to death during the first month of experiment. For this reason, subsequent treatments were realized in larger volumes of water.

Otherwise, in placebo fish, mortality was higher under a photoperiod of 12-L:12-D than in the dark. This mortality can be explained by the fact that stress caused by the manipulation was lessened by darkness (Britz and Pienaar, 1992). In contrast, significant percent mortality observed in treated fish kept in the dark, compared with treated fish maintained under a photoperiod of 12-L:12-D and with placebo fish (under a 12-L:12-D regime or in the dark) indicates that when fish were deprived of visual and tactile sensory cues, the stress caused engendered a consequential mortality.

\subsection{Feed rhythm and specific growth rate}

Differences in specific growth rate, feed rhythm, average number of self-feeder activations and percentage daily feed intake (relative to body weight), observed among the tanks could not be due to artifacts. At the beginning of the experiment, average weights of fish were similar in each tank. Although anesthesia with clove essence could have been responsible for a temporary decrease in on-demand feeding behavior (Pirhonen and Schreck, 
2002), this anesthesia was carried out on all fish groups. Likewise, all sea bass could feed freely according to their appetite. These fish are known to be able to trigger a self-feeder system during the day and also at night (Sanchez-Vasquez et al., 1994; Bégout-Anras, 1995; Boujard et al., 1996; Madrid et al., 1997; Coves et al., 1998; Aranda et al., 2000; Gardeur et al., 2001; Rubio et al., 2004). In addition, each activation of the self-feeder was followed by the consumption of distributed pellets: indeed, during the four months of experiment, only $0.15 \%$ of supplied pellets was wasted.

Under a 12-L:12-D photoperiod, sea bass mainly presented a diurnal feed rhythm. This pattern corroborates previous observations made in the same fish species (Bégout-Anras, 1995; Madrid et al., 1997; Aranda et al., 1999a, b; Boujard et al., 2000; Paspatis et al., 2003; Rubio et al., 2003). Indeed, European sea bass is well known to present a diurnal feed rhythm in spring and summer but a nocturnal one in autumn and winter (Sanchez-Vasquez et al., 1998; Rubio et al., 2004). However, this dual feeding behavior in sea bass is not always so marked (Sanchez-Vasquez et al., 1995a, b; Boujard et al., 1996; Rubio et al., 2004). In this study, fish kept in the dark showed no diel variation in feeding behavior. Under a photoperiod of 12-L:12-D, however, fish presented a peak in feed demand immediately after the artificial dawn, feed demand then decreased progressively over the rest of the day until the artificial dusk. This variation in feed demand during the photophase has previously been observed in European sea bass (Sanchez-Vasquez et al., 1995b; Madrid et al., 1997). In the present study, in darkness or under a photoperiod of 12-L:12-D, sea bass daily consumed about $0.87 \%$ of their body weight. This consumption rate corroborated recent results of Coves and Dutto (com. pers.) indicating that sea bass daily consumed about $0.95 \%$ of their body weight under a 12-L:12-D regime and about $0.8 \%$ of their body weight per day in continuous darkness. This suggests that the stress caused by the monthly fish manipulation did not modify fish feeding motivation. 
Photoperiod modified not only sea bass feed rhythm but also the amount of food they ingested. Indeed, the number of self-feeder activations as well as feed intake were greater and uneaten food lower under a photoperiod of 12-L:12-D than in the dark. This manifested itself by a overall specific growth rate, recorded over the entire duration of the experiment, higher in sea bass maintained under a photoperiod of 12-L:12-D than in fish kept in the dark. This observation corroborates many studies on different fish species and can be explained by reduced food detection efficiency in low light or in darkness (Appelbaum, 1979; Appelbaum and Riehl, 1997; Rubio et al., 2003). For example, fish with cataracts present a reduced growth rate (Bjerkås et al., 1996). In the same way, the ability of some fish species from New Zealand rivers to feed on moving prey is significantly reduced when turbidity increases (Rowe et al., 2002).

\subsection{Roles of lateral system in on-demand feeding behavior}

In our experimental conditions, and particularly in the dark, the inactivation of lateral system did not affect feed intake, specific growth rate and feed efficiency. Only feed demand was reduced in fish deprived of their lateral system. These results demonstrated that in our experimental conditions, sea bass lateral system is not the major sensory organ permitting nocturnal feeding. One can suggest that chemoreception is likely the basis of this nocturnal feeding ability. Since the recent work of Rubio et al. (2003), we know that rapid retrieval of pellets (less than $20 \mathrm{sec}$ ) very significantly penalizes food capture by sea bass in the dark. In our experimental system, pellet availability was greater than 10 min and we can assume that olfaction alone could ensure the localization of food pellets, leading to similar performances in treated and placebo sea bass. Nevertheless, many authors (Enger et al., 1989; Montgomery and Hamilton, 1997; New et al., 2001; Pohlmann et al., 2004) think that if olfaction plays a 
preponderant role in feeding behavior, it is not sufficient to localize and catch a prey in the dark. In contrast, our results show that European sea bass is able to feed in the dark, guided only by olfaction provided that its targets (self-feeder and pellets) are relatively motionless. We can ask whether it would be the same for a lower time of pellet availability. Rubio et al. (2003) demonstrated that sea bass moving in total darkness showed a catch efficiency of 78.6 $\%$ for a pellet availability time lower than $20 \mathrm{sec}$. This is a catch process still very efficient but we cannot assess whether it depends only on olfaction or whether an association chemoreception - mechanoreception occurs. Whether lateral system helps nocturnal feeding of fish under rearing conditions, it remains to be investigated under conditions of rapid pellet retrieval, what our experimental system did not allow to realize. This potential role of lateral system in pellet localization across the height of water column in a sea cage must be taken into account as lateral system efficiency was largely demonstrated in localization and catch of live moving prey (Hoekstra and Janssen, 1985; Montgomery, 1989; Bleckmann, 1993; Liang et al., 1998; Liao and Chang, 2003; Pohlmann et al., 2004).

Although sea bass olfactive abilities can explain why percent feed intake in placebo and treated fish were similar, the observation of specific growth rates greater in treated than in placebo fish highlights the probable action of one or more other mechanisms in facilitating feeding and growth.

\subsection{Role of antibiotics}

The recurrent use of an antibiotic in order to inactivate the sea bass lateral system could be responsible of this favorable effect on growth in treated fish. Dabrowski and Poczyczyński (1987) already observed such an effect of antibiotic on fish growth. Three action mechanisms are possible. First, antibiotics incorporated into food ration could interfere 
with pathogenic agents in fish digestive tract without being absorbed by digestive mucous membrane. This might result in a reduction of overall metabolic, decrease in toxin production, or both, leading to improvement in the general state of the animal that could accelerate growth (Dantzer and Mormède, 1979). Second, antibiotics increase food digestibility (Choubert et al., 1991), and particularly that of unsaturated fatty acids (Cravedi et al., 1987). The better digestibility of food in sea bass treated with antibiotics could increase assimilation and satiety, hence reducing their feeding demand. Third, antibiotic could increase permeability of intestinal mucosa (March and Briely, 1967). Consequently, in our study, antibiotic treatment could be responsible for a "booster" effect on fish growth, which could explain their greater growth rate.

To conclude, in the dark, sea bass deprived of their lateral system presented a specific growth rate greater than that of placebo fish. This result could be explained by the intervention of a mechanism of sensory compensation likely provided by the olfactive system, the more efficient because the targets are practically motionless plus the "booster" action of antibiotics on treated fish. In order to answer the question as to whether lateral system facilitates feeding at night, it would be interesting to repeat this experiment by substituting for the antibiotic use by surgery alone to inactivate fish lateral system. In addition, the effect of disactivating lateral system on nocturnal feeding behavior will have to be researched in quick pellet transit equaling to moving living prey trajectories or using living moving preys. This would permit the function of lateral system to be investigated under conditions closer to these experimented in nature.

\section{Acknowledgements}


We wish to thank Ian Jenkinson for improving the English language. This study was conducted under the approval of the Animal Care Committee of France under the official license of J.P. Lagardère (no. 02526) and was supported by a grant (K.F.) from the Conseil

Général de Charente Maritime.

\section{References}

Appelbaum, S., 1979. Die bedeutung der chemischen, optischen und mechanischen perzetion für das verhalten einiger süßwasserfische beim nahrungserwerb, insbesondere im larvalen stadium, ein beitrag zur aquakultur. Dr. Thesis Univ. Hamburg, Germany.

Appelbaum, S., Riehl, R., 1997. Scanning electron microscopic observations of the chemoand mechanoreceptors of carp larvae (Cyprinus carpio) and their relatioship to early behaviour. Aquat. Living Resour. 10, 1-12.

Aranda, A., Madrid, J.A., Zamora, A.S., Sanchez-Vasquez, F.J., 1999a. Synchronizing Effect of Photoperiod on the Dual Phasing of Demand-Feeding Rhythms in Sea Bass. Biol. Rhythm Res. 30(4), 392-406.

Aranda, A., Sanchez-Vasquez, F.J., Madrid, J.A., 1999b. Influence of water temperature on demand-feeding rhythms in sea bass. J. Fish Biol. 55(5), 1029-1039.

Aranda, A., Sánchez-Vásquez, F.J., Zamora, S., Madrid, J.A., 2000. Self-design of fish diets by means of self-feeders: validation of procedures. J. Physiol. Biochem. 56(3), 155-166.

Atema, J., 1988. Distribution of chemical stimuli. In: Atema, J., Fay, R.R., Popper, A.N., Tavolga, W.N. (Eds), Sensory Biology of Aquatic Animals. Springer-Verlag, NewYork, pp. 29-56.

Bégout-Anras, M.L., 1995. Demand-feeding behaviour of sea bass kept in ponds: diel and seasonal patterns, and influences of environmental factors. Aquacult. Internat. 3, 186195. 
Bjerkås, E., Waagbø, R., Sveier, H., Breck, O., Bjerkås, I., Bjørnestad, E., Maage, A., 1996. Cataract development in Atlantic salmon (Salmo salar L) in fresh water. Acta Vet. Scand. 37, 351-360.

Blaxter, J.H.S., Fuiman, L.A., 1989. Function of the free neuromasts of marine teleost larvae. In: Coombs, S., Görner, P., Münz H. (Eds.), the mechanosensory lateral line, neurobiology and evolution. New York, Springer Verlag, pp. 481-499.

Bleckmann, H., 1993. Role of the lateral line in fish behaviour. In: Pitcher, T. J., The Behaviour of Teleost Fishes $2^{\text {nd }}$ ed. London, Chapman and Hall, 201-246.

Boujard, T., Jourdan, M., Kentouri, M., Divanach, P., 1996. Diel feeding activity and the effect of time-restricted self-feeding on growth and feed conversion in European sea bass. Aquaculture 139, 117-127.

Boujard, T., Gélineau, A., Corraze, G., Kaushik, S., Gasset, E., Coves, D., Dutto, G., 2000. Effect of dietary lipid content on circadian rhythm of feeding activity in European sea bass. Physiol. Behav. 68, 683-689.

Britz, P.J., Pienaar, A.G., 1992. Laboratory experiments on the effects of light and cover on the behaviour and growth of African catfish, Clarias gariepinus (Pisces: Clariidae). J. Zool. 227(1), 43-62.

Choubert, G., de la Noüe, J., Lésel, R., 1991. Effects of dietary fat levels and of antibiotics (Flumequine + Gentamicin) on nutrient digestibility in rainbow trout, Oncorhynchus mykiss (Walbaum). Aquat. Living Resour. 4, 147-153.

Cobcroft, J.M., Pankhurst, P.M., 2003. Sensory organ development in cultured striped trumpeter larvae Latris lineata: implications for feeding behavior. Mar. Freshwater Res. $54,669-682$.

Coombs, S., Braun, C.B., Donovan, B., 2001. The orienting response of Lake Michigan mottled sculpin is mediated by canal neuromasts. J. Exp. Biol. 204, 337-348. 
Coves, D., Gasset, E., Lemarié, G., Dutto, G., 1998. A simple way of avoiding feed wastage in European seabass, Dicentrarchus labrax, under self-feeding conditions. Aquat. Living Resour. 11(6), 395-401.

Cravedi, J.P., Choubert, G., Delous, G., 1987. Digestibility of chloramphenicol, oxolinic acid and axytetracycline in rainbow trout and influence of these antibiotics on lipid digestibility. Aquaculture 60, 133141.

Dabrowski, K., Poczyczyński, P., 1988. Comparative experiments on starter diets for grass carp and common carp. Aquaculture 69(3-4), 317-332.

Dantzer, R., Mormède, P., 1979. Le stress en élevage intensif. Actualités scientifiques et agronomiques de l'I.N.R.A. MASSON, Paris, New York, Barcelone, Milan. 117 pp.

Enger, P.S., Kalmijn, A.J., Sand, O., 1989. Behavioral investigations on the functions of the lateral line and inner ear in predation. In: Coombs, S., Görner, P., Münz, H., The mechanosensory lateral line, neurobiology and evolution. New York, Springer Verlag, $575-587$.

Fernald, R.D., 1988. Aquatic adaptations in fish eyes. In: Atema, J., Fay, R.R., Popper, A.N., Tavolga, W.N., Sensory Biology of Aquatic Animals. Springer-Verlag, New-York, 435466.

Gardeur, J.-N., Lemarié, G., Coves, D., Boujard, T., 2001. Typology of individual growth in sea bass (Dicentrarchus labrax). Aquat. Living Resour. 14, 223-231.

Ghysen, A., Dambly-Chaudière, C., 2004. Development of the zebrafish lateral line. Curr. Op. Neurobiol. 14, 67-73.

Hara, T.J., 1993. Role of olfaction in fish behavior. In: Pitcher, TJ., The Behaviour of Teleost Fishes, $2^{\text {nd }}$ ed. London, Chapman and Hall, pp. 171-199.

Harder, W., 1975. Anatomy of fishes. E. Schweizerbart'sche Verlagsbuchhandlung (Nägele u. Obermiller), Stuttgart. $351 \mathrm{pp}$. 
Hoekstra, D., Janssen, J., 1986. Lateral line receptivity in the mottled sculpin (Cottus bairdi). Copeia 1, 91-96.

Hyatt, K.D., 1979. Feeding strategy. In: Hoar, W.S., Randall, D.J., Brett, J.R., Fish physiology, 8, Bioenergetics and growth, Academic Press, pp. 71-119.

Kaus, S., 1987. The effect of aminoglycoside antibiotics on the lateral line organ of Aplocheilus lineatus (Cyprinodontidae). Acta Oto-laryng. (Stockh) 103, 291-298.

Lamb, C.F., 2001. Gustation and feeding behavior. In: Houlihan, D., Boujard, T., Jobling, M., Food intake in Fish, Iowa State University Press, U.S.A., pp. 108-130.

Liang, X.F., Liu, J.K., Huang, B.Y., 1998. The role of sense organs in the feeding behaviour of chinese perch. J. Fish Biol. 52, 1058-1067.

Liao, I.C., Chang, E.Y., 2003. Role of sensory mechanisms in predatory feeding behavior of juvenile red drum Sciaenops ocellatus. Fish. Sci. 69, 317-322.

McDowall, R.M., 1997. An accessory lateral line in some New Zealand and australian galaxiids (teleostei: Galaxiidae). Ecol. Freshw. Fish 6, 217-224.

Madrid, J.A., Azzaydi, M., Zamora, S., Sánchez-Vásquez, F.J., 1997. Continuous recording of uneaten food pellets and demand-feeding activity: a new approach to studying feeding rhythms in fish. Physiol Behav. 62(4), 689-695.

March, B.E., Biely, J., 1967. A re-assessment of the mode of action of the growth-stimulating properties of antibiotics. Poult. Sci. 46, 831-838.

Montgomery, J.C., 1989. Lateral detection of planktonic prey. In: Coombs, S., Görner, P., Münz, H., The mechanosensory lateral line, neurobiology and evolution, New York, Springer Verlag, pp. 561-573.

Montgomery, J.C., Milton, R.C., 1993. Use of the lateral line for feeding in the torrentfish (Cheimarrichthys fosteri). N. Z. J. Zool. 20, 121-125. 
Montgomery, J.C., Hamilton, A.R., 1997. Sensory contributions to nocturnal prey capture in the dwarf scorpion fish (Scorpaena papillosus). Mar. Freshw. Behav. Physiol. 30, 209223.

New, J.G., Alborg Fewkes, L., Khan, A.N., 2001. Strike feeding behavior in the muskellunge, Esox masquinongy: contributions of the lateral line and visual sensory systems. J. Exp. Biol. 204, 1207-1221.

Partridge, B.L., 1982. The structure and function of fish schools. Sci. Am. 246(6), 114-123.

Partridge, B.L., Pitcher, T.J., 1980. The sensory basis of fish schools: relative roles of lateral line and vision. J. Comp. Physiol. 135, 315-325.

Paspatis, M., Boujard, T., Maragoudaki, D., Blanchard, G., Kentouri, M., 2003. Do stocking density and feed reward level affect growth and feeding of self-fed juvenile European sea bass? Aquaculture 216, 103-113.

Pavlov, D.S., Kasumyan, A.O., 1990. Sensory principles of the feeding behavior of fishes. J. Ichthyol. 6, 77-93.

Pirhonen, J., Schreck, C.B., 2002. Effects of anaesthesia with MS-222, clove oil and CO2 on feed intake and plasma cortisol in steelhead trout (Oncorhynchus mykiss). Aquaculture $62248,1-8$

Pitcher, T.J., Partridge, B.L., Wardle, C.S., 1976. A blind fish can school. Science. 194, 963965.

Pohlmann, K., Atema, J., Breithaupt, T., 2004. The importance of the lateral line in nocturnal predation of piscivorous catfish. J. Exp. Biol. 207, 2971-2978.

Rowe, D.K., Smith, J.P., Williams, E., 2002. Effects of turbidity on the feeding ability of adult, riverine smelt (Retropinna retropinna) and inanga (Galaxia maculatus). N. Z. J. Mar. Freshw. Res. 36, 143-150. 
Rubio, V.C., Sánchez-Vásquez, F.J., Madrid, J.A., 2003. Nocturnal feeding reduces sea bass (Dicentrarchus labrax, L.) pellet-catching ability. Aquaculture 220, 697-705.

Rubio, V.C., Vivas, M., Sánchez-Mut, A., Sánchez-Vásquez, F.J., Coves, D., Dutto, G., Madrid, J.A., 2004. Self-feeding of European sea bass (Dicentrarchus labrax, L.) under laboratory and farming conditions using a string sensor. Aquaculture 233, 393-403.

Sánchez-Vásquez, F.J., Martínez, F.J., Zamora, S., Madrid, J.A., 1994. Design and performance of an accurate demand feeder for the study of feeding behaviour in sea bass, Dicentrarchus labrax L. Physiol. \& Behav. 56(4), 789-794.

Sánchez-Vásquez, F.J., Zamora, S., Madrid, J.A., 1995a. Light-dark and food restriction cycles in sea bass: effect of conflicting zeitgebers on deman-feeding rhythms. Physiol. Behav. 58(4), 705-714.

Sánchez-Vásquez, F.J., Madrid, J.A., Zamora, S., 1995b. Circadian rhythms of feeding activity in sea bass, Dicentrarchus labrax L.: dual phasing capacity of diel demandfeeding pattern. J. Biol. Rhythms. 10(3), 256-266.

Sánchez-Vásquez, F.J., Azzaydi, M., Martínez, F.J., Zamora, S., Madrid, J.A., 1998. Annual rhythms of demand-feeding activity in sea bass: evidence of a seasonal phase inversion of the diel feeding pattern. Chronobiology International. 15(6), 607-622.

Song, J., Yan, H.Y., Popper, A.N., 1995. Damage and recovery of hair cells in fish canal (but not superficial) neuromasts after gentamicin exposure. Hear. Res. 91, 63-71.

Tavolga, W.N., 1977. Mechanisms for directional hearing in the sea catfish (Arius felis). J. Exp. Biol. 67, 97-115. 
Table 1. Influence of lateral system inactivation on sea bass feeding behavior. Mortality, average daily number of feed demands, feed intake, overall specific growth rate $\left(\mathrm{SGR}_{\mathrm{o}}\right)$ and feed efficiency are reported according to photoperiod (12-L:12-D and darkness) and treatment (placebo fish, treated fish and fish from mixed tanks). In mixed tanks, the individual tagging of fish allowed to calculate independently percent mortality of treated and placebo fish. Data obtained were taken into account in the calculation of percent mortality for all placebo fish and all treated fish.

\begin{tabular}{|c|c|c|c|c|c|c|}
\hline \multirow[b]{2}{*}{ L:D } & \multicolumn{2}{|c|}{$\begin{array}{c}\text { Placebo fish } \\
(0 \% \text { treated fish })\end{array}$} & \multicolumn{2}{|c|}{$\begin{array}{c}\text { Mixed tanks } \\
\text { (50\% treated fish) }\end{array}$} & \multicolumn{2}{|c|}{$\begin{array}{c}\text { Treated fish } \\
\text { (100\% treated fish) }\end{array}$} \\
\hline & $12: 12$ & Darkness & $12: 12$ & Darkness & $12: 12$ & Darkness \\
\hline $\begin{array}{l}\text { Average number of } \\
\text { daily feed demands }\end{array}$ & $\begin{array}{c}23.2 \pm 10.2 \\
220\end{array}$ & $\begin{array}{c}16.8 \pm 10.7 \\
220\end{array}$ & $\begin{array}{c}24.4 \pm 10.5 \\
220\end{array}$ & $\begin{array}{c}16.4 \pm 9.6 \\
220\end{array}$ & $\begin{array}{c}20.3 \pm 10.0 \\
220\end{array}$ & $\begin{array}{c}13.5 \pm 7.5 \\
110\end{array}$ \\
\hline $\operatorname{SGR}_{\mathrm{o}}(\%)$ & $\begin{array}{c}0.66 \pm 0.19 \\
70 \\
\end{array}$ & $\begin{array}{c}0.44 \pm 0.12 \\
83 \\
\end{array}$ & $\begin{array}{c}0.67 \pm 0.13 \\
70 \\
\end{array}$ & $\begin{array}{c}0.55 \pm 0.14 \\
68 \\
\end{array}$ & $\begin{array}{c}0.68 \pm 0.17 \\
56 \\
\end{array}$ & $\begin{array}{c}0.55 \pm 0.13 \\
24 \\
\end{array}$ \\
\hline Feed efficiency (\%) & $\begin{array}{c}62.2 \pm 11.1 \\
8\end{array}$ & $\begin{array}{c}58.4 \pm 12.4 \\
8\end{array}$ & $\begin{array}{c}60.6 \pm 11.1 \\
8\end{array}$ & $\begin{array}{c}62.1 \pm 10.1 \\
8\end{array}$ & $\begin{array}{c}62.9 \pm 14.7 \\
8\end{array}$ & $\begin{array}{c}54.1 \pm 19.2 \\
4\end{array}$ \\
\hline
\end{tabular}


Figure legends

Fig. 1. Effect of sectioning lateral system nerves followed by antibiotic treatment (gentamicin and streptomycin) on tissue state of both types of sea bass trunk neuromasts observed by scanning electron microscopy. A, B. Intact superficial (A) and canal (B) neuromasts observed in placebo fish. Superficial neuromast is still recovered by its cupula (A) whereas its absence on canal neuromast reveals subjacent hair bundles (inset in B). C, D. Superficial (C) and canal (D) neuromasts damaged by the double treatment. Dotted areas are magnified in insets: hair bundles inside superficial (C) and canal (D) neuromasts were disorganized.

Fig. 2. Average daily feed rhythm of sea bass maintained under a photoperiod of 12-L:12-D (6 tanks, A) and of sea bass kept in the dark (5 tanks, B). Vertical bars represent the standard deviation of average number of daily feed demands.

Fig. 3. A. Average number of daily feed demands of sea bass according to photoperiod (12L:12-D and darkness) and treatment (placebos, fish from mixed tanks and treated fish). Under the photoperiod of 12-L:12-D, sea bass presented a feed demand greater than that observed in the dark. Treated sea bass showed a feed demand lower than fish from mixed tanks and placebo fish. Vertical bars represent the standard deviation of average number of daily feed demands. B. Feed intake (g pellets ingested per $100 \mathrm{~g}$ average body weight) of sea bass according to photoperiod (12-L:12-D and darkness) and treatment (placebo fish, fish from mixed tanks and treated fish). For the photoperiod of 12-L:12-D, feed intake was greater than in the dark. Treatment did not significantly influence feed intake. Vertical bars represent the standard deviation of average number of daily feed demands. 
Fig. 4. A. Average overall specific growth rate $\left(\mathrm{SGR}_{\mathrm{o}}\right)$ of fish according to photoperiod and percentage of treated fish in tanks. The $\mathrm{SGR}_{\mathrm{o}}$ of fish maintained under a photoperiod of 12L:12-D was greater than that of fish kept in the dark. Under the photoperiod of 12-L:12-D, sea bass presented a constant $\mathrm{SGR}_{\mathrm{o}}$ whatever was treatment. In the dark, $\mathrm{SGR}_{\mathrm{o}}$ of placebo fish was lower than that of treated fish and that of fish from mixed tanks. Vertical bars represent the standard deviation of average $\mathrm{SGR}_{0}$. B. Feed efficiency of ingested food in biomass of fish according to the two factors studied: photoperiod (12-L:12-D and darkness) and treatment (placebo, fish from mixed tanks and treated fish). Neither illumination regime nor treatment did modify feed efficiency. 
A

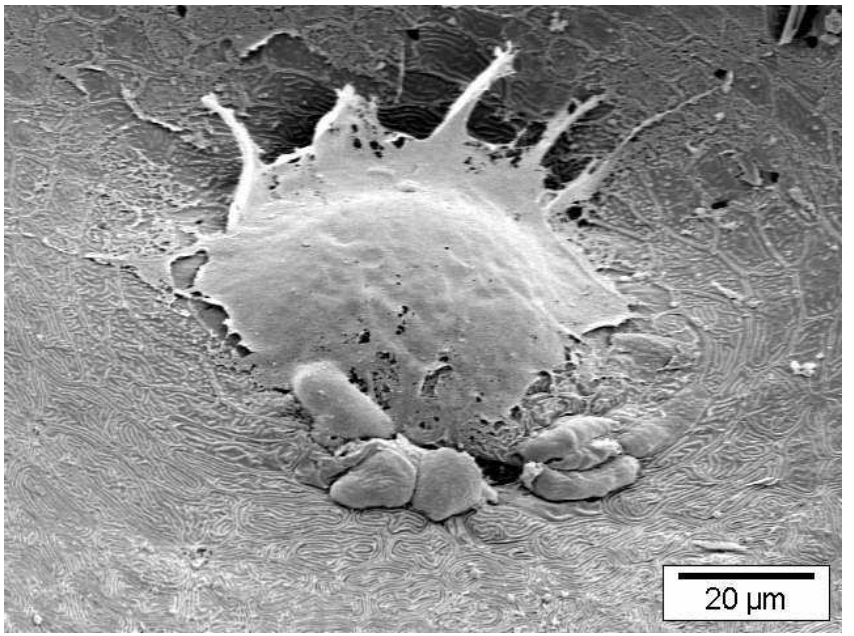

C

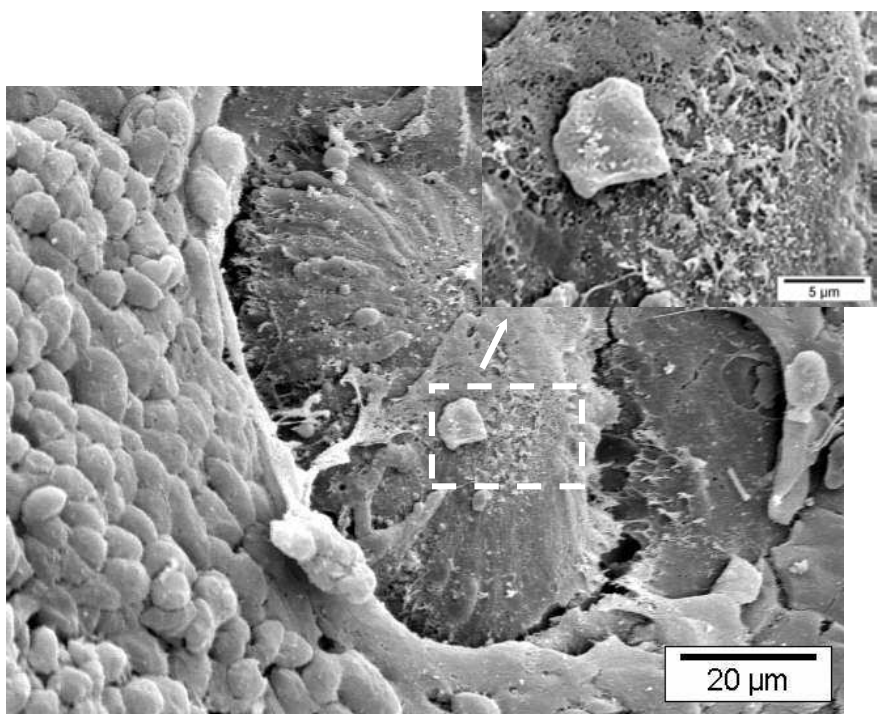

B

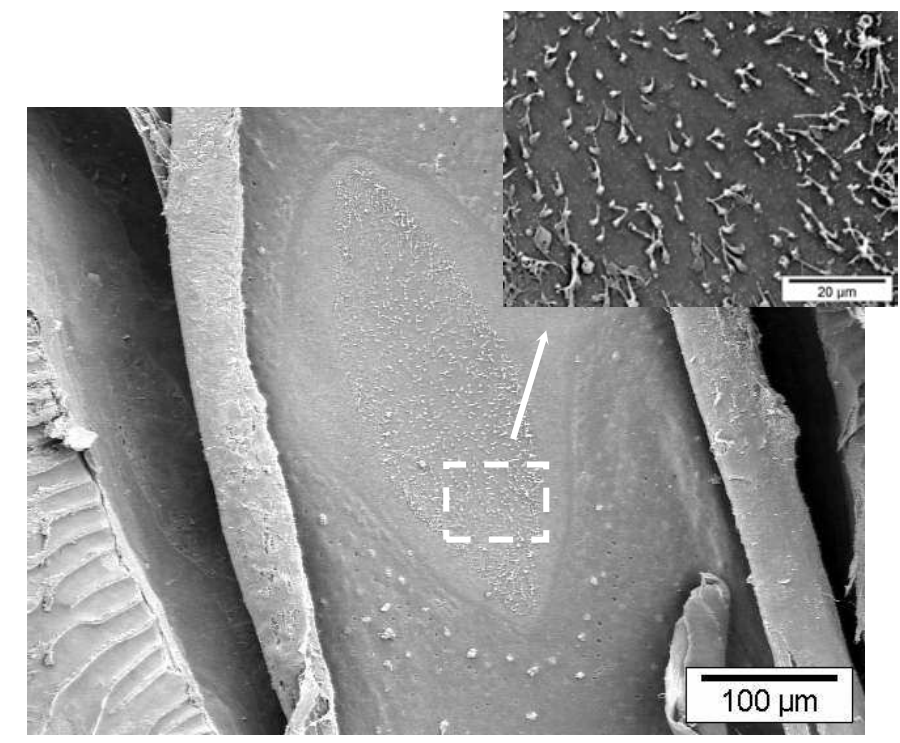

D

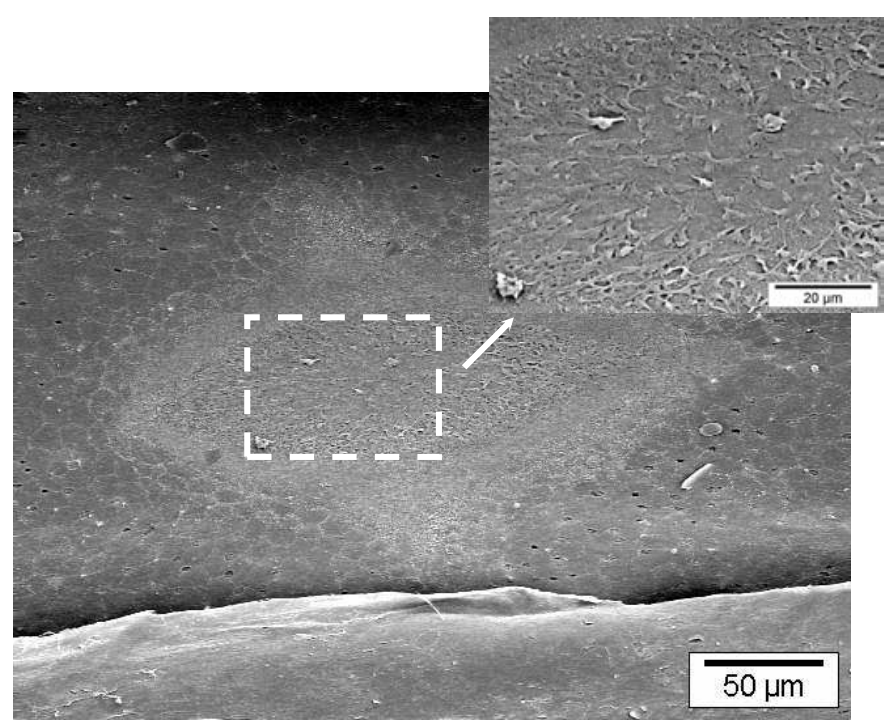


A

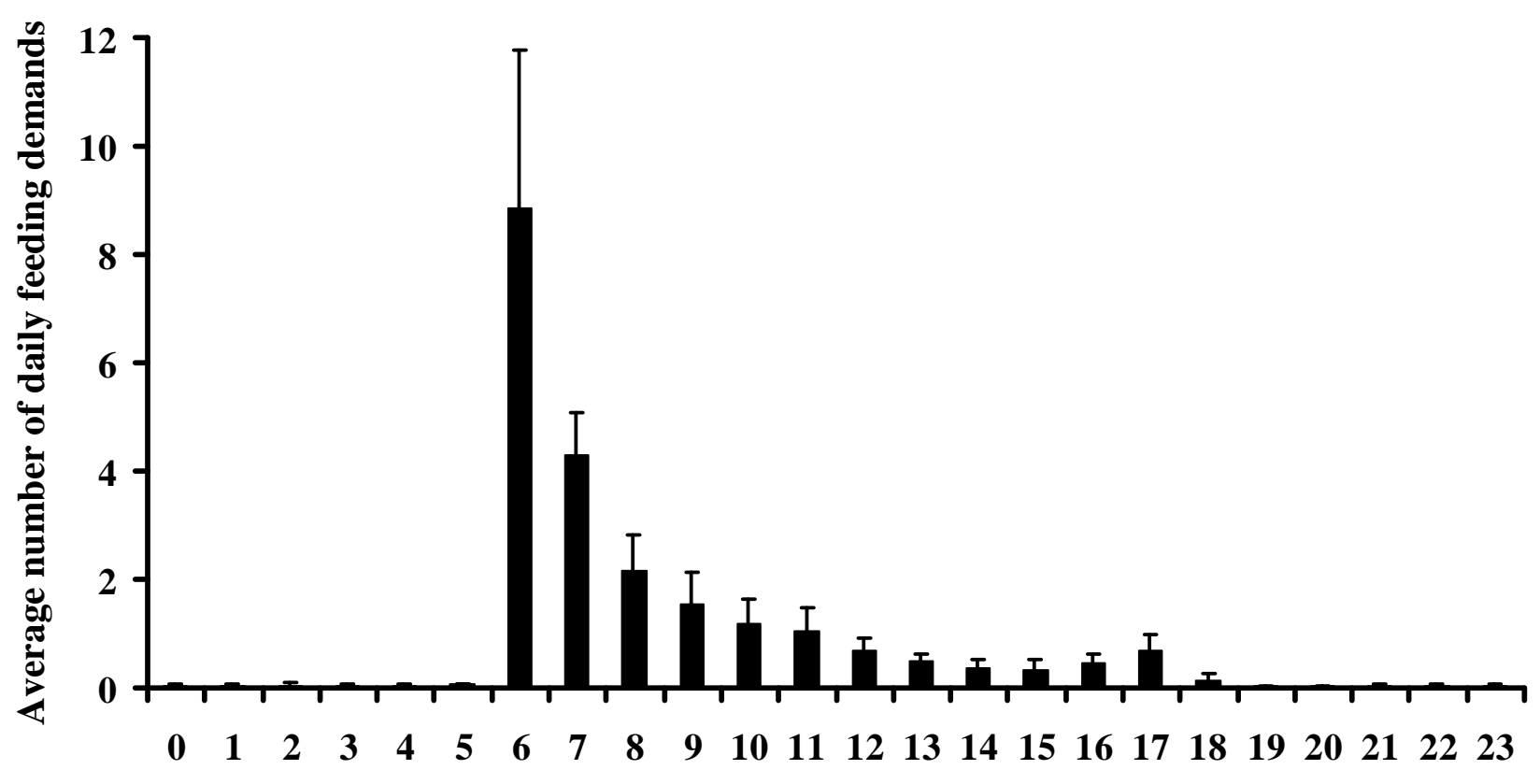

Time of the day

B

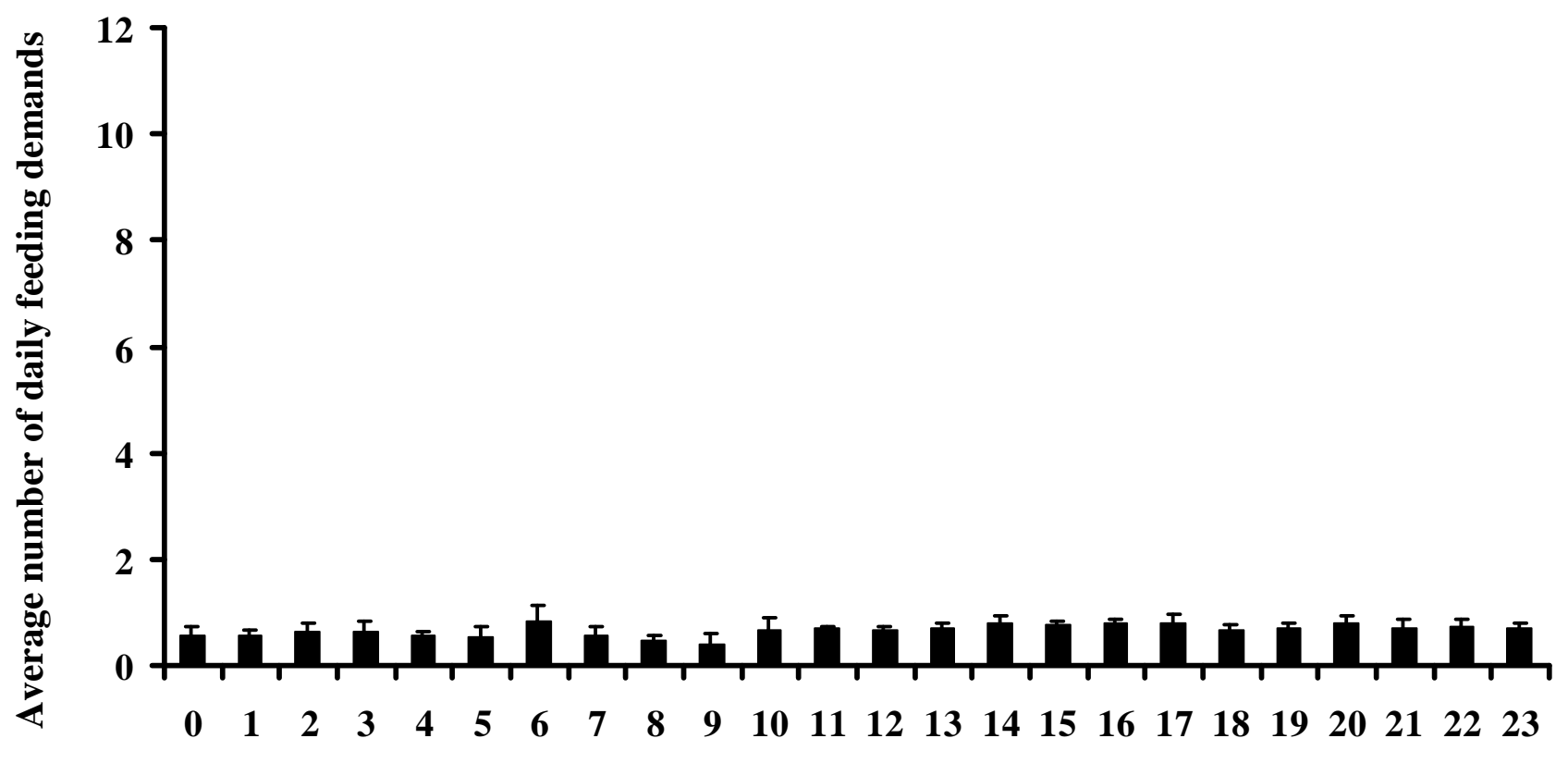

Time of the day 
A

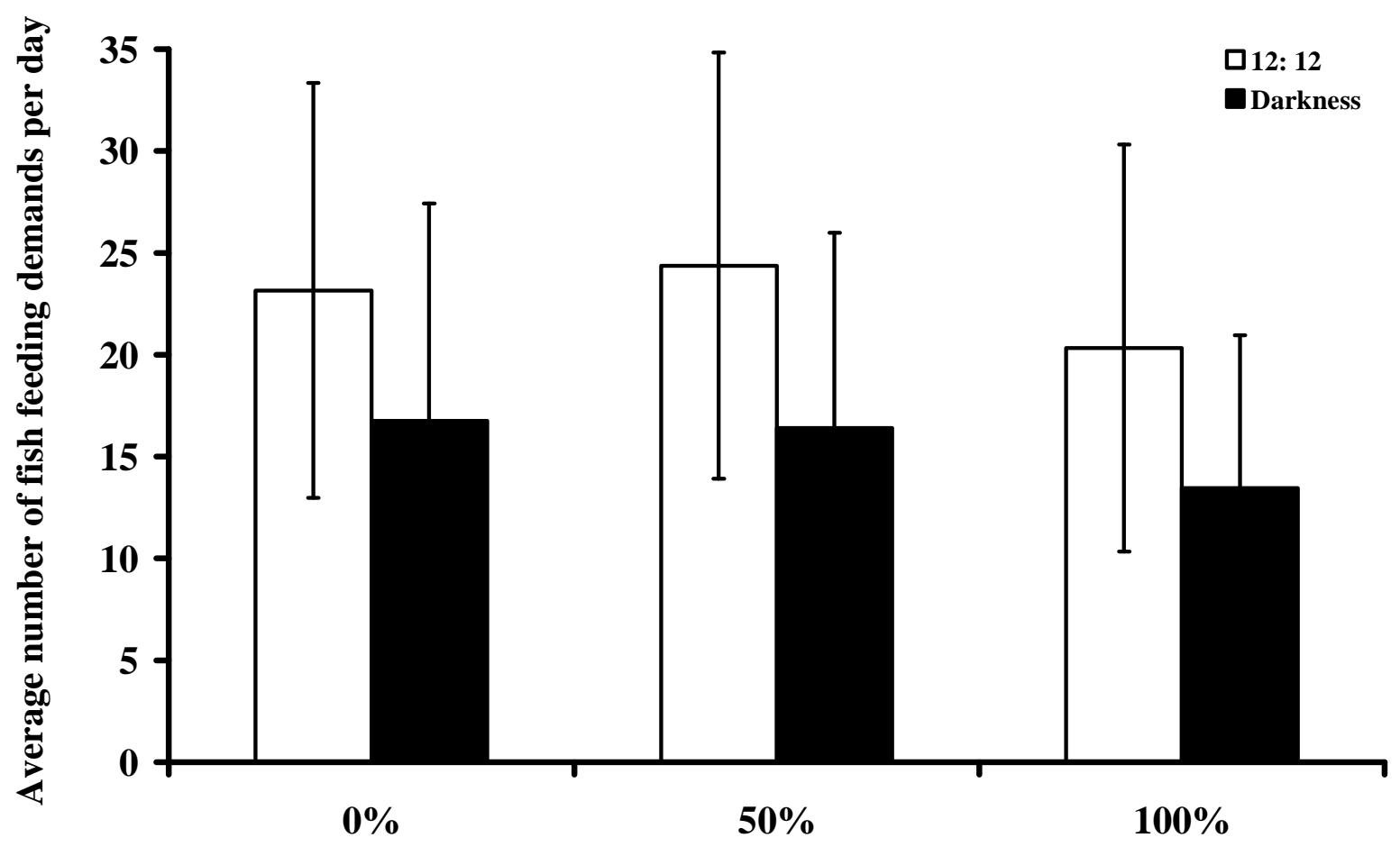

Percentage of treated fish per tank

B

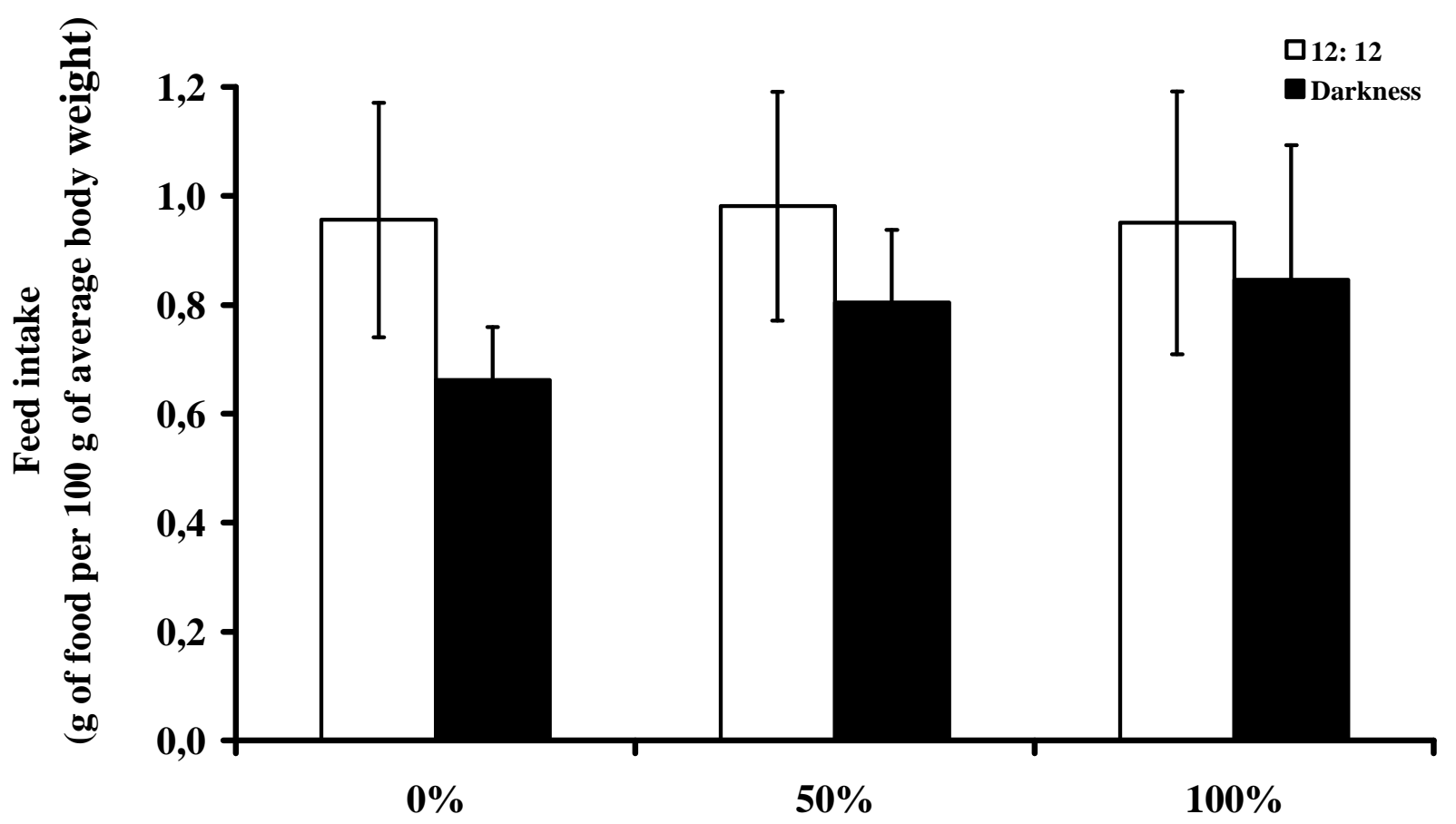

Percentage of treated fish per tank 
A

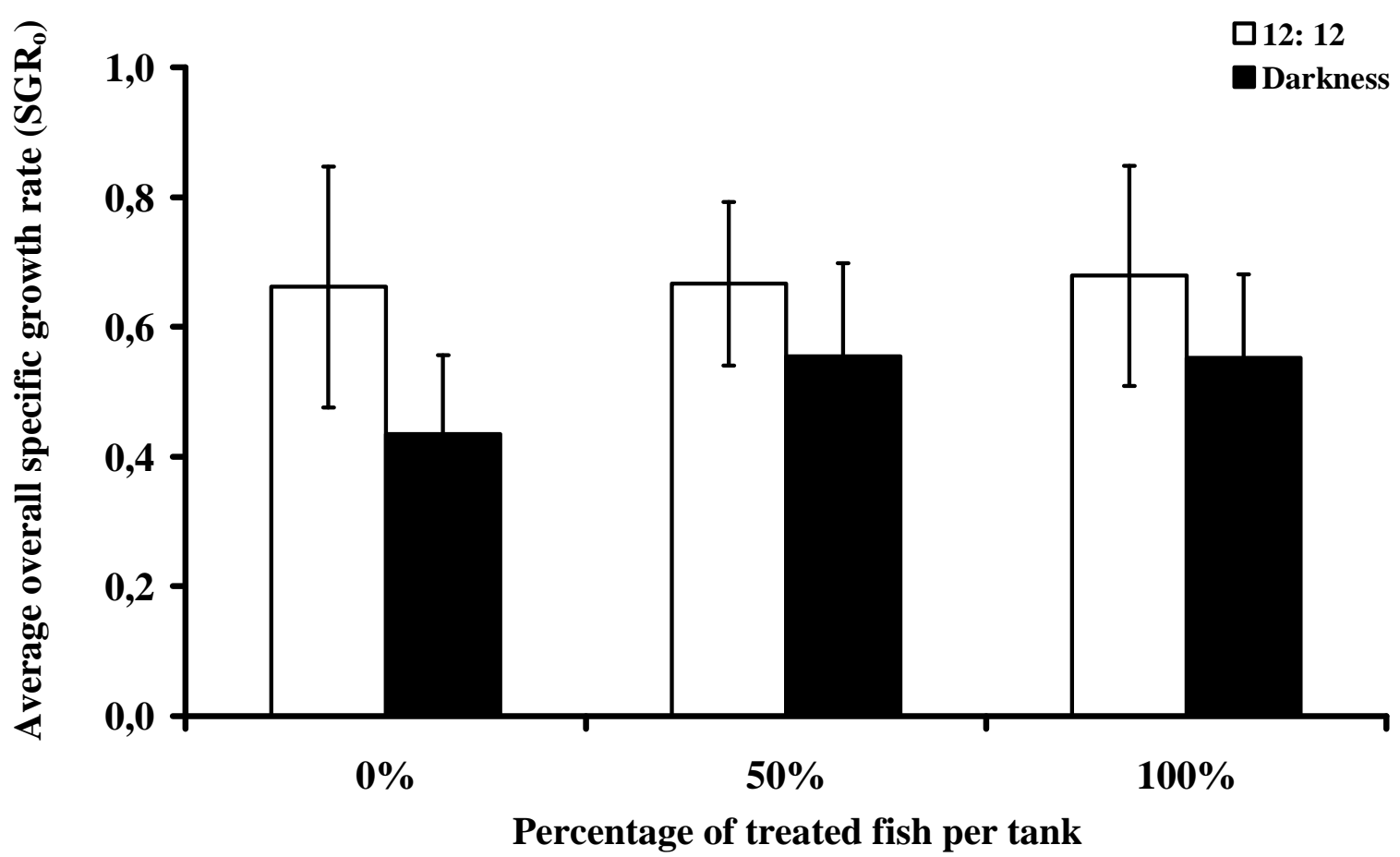

B

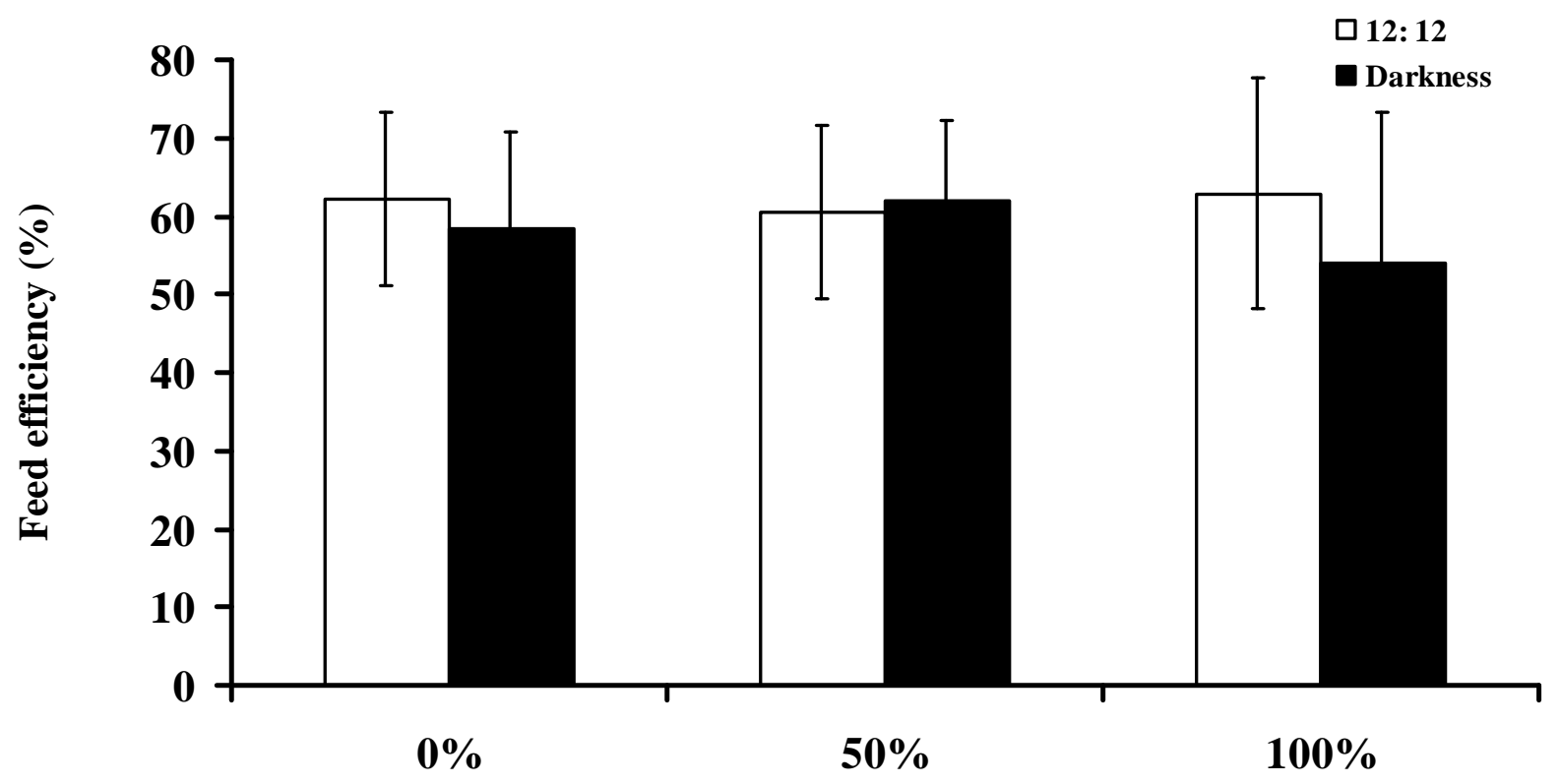

Percentage of treated fish per tank 